\title{
Self-care behavior and associated factors among patients with Type 2 Diabetes in Hossana, Southern Ethiopia: The Health Belief Model Perspective
}

Ravi Prakash ( $\square$ ravi.82@outlook.com )

WCU: Wachemo University https://orcid.org/0000-0003-0635-9287

Lonsako Abute

WCU: Wachemo University

Belay Erchafo

WCU: Wachemo University

Tegegn Tadesse

WCU: Wachemo University

Tirulo Kedir

WCU: Wachemo University

Tagesse Sedoro

WCU: Wachemo University

Temesgen Tamirat

WCU: Wachemo University

Addiselam Gizachew

WCU: Wachemo University

\section{Research}

Keywords: Self-care Behavior, Diabetes, Health Belief Model

Posted Date: May 11th, 2021

DOl: https://doi.org/10.21203/rs.3.rs-508773/v1

License: (1) (1) This work is licensed under a Creative Commons Attribution 4.0 International License.

Read Full License 


\section{Abstract \\ Background}

Diabetes a chronic disease requires lifelong medical treatments and life-style adjustment. Hence, it requires dedication towards self-care behavior in multiple domains. We aimed to identify determinants of self-care behavior among patients with diabetes through Health Belief Model Perspective.

\section{Methods}

A cross-sectional study was conducted on 276 patients with simple random sampling technique. The level of self-care behavior on diabetic patients was measured using parameters of physical exercise, diet, medication and blood glucose. Bivariate and multivariable logistic regression analyses were conducted.

\section{Results}

Approximately, 119 (43.1\%) of them practiced recommended self-care practices. Patients with more information performed 3 times more self-care $(\mathrm{OR}-3.07 ; 95 \% \mathrm{Cl} 0.19-7.9)$ than less informed patients. Individuals with high income performed two times more self-care than less income (OR-2.42;95\% $\mathrm{Cl} 1.04-$ 17.95). High perceived severity was 8 times more likely to performed for self-care than less perceived severity (OR-8.3,95\%Cl1.19-16.25).

\section{Conclusion}

Status of self-care practices on diabetic patients is lower than studies in other areas. Training should be focused on perceived severity of diabetes and how to overcome perceived barriers for self-care by increasing the frequency and reach out message on diabetes.

\section{Background:}

Diabetes mellitus is one of the serious chronic disease which affects well-being of mankind including families and societies. It's among one of the top 10 causes of death and has estimated approximately 4 million deaths globally in $2017 .{ }^{1}$ Type 2 Diabetes (T2D) accounts for $90 \%$ of the total diabetes cases and this much of rise can be attributed by various factors such as, ageing, urban migration of the people (urbanization) and obesogenic environment. The global prevalence of T2D is estimated to be 463 million people (9.3\%) which might rise to $10.2 \%$ (578 million affected people) in 2030 and 10.9\% (700 million affected people) in 2045. Also, the prevalence has bene observed more in urban population (10.8\%) and high income countries (10.4\%) than rural population (7.2\%) and low income countries (4.0\%). Moreover, $50.1 \%$ of the people (one in two) have no idea that they are diabetic and living with diabetes. ${ }^{2}$ In recent 
years, the number of young adults with $\mathrm{T} 2 \mathrm{D}$ is also increased and contributing for increase in $\mathrm{T} 2 \mathrm{D}$ prevalence via their longer survival.

T2D is a metabolic disorder that increases blood sugar level (causes hyperglycemia) as a result of defected insulin secretion. This involves various interactions between genetic, environmental and behavioral risk factors. ${ }^{3,4}$ Individuals affected with T2D usually vulnerable to show and long term complications and sometimes lead to premature death too. Life style and genetic factors of any individual are primarily responsible for T2D. ${ }^{5}$ Some of these factors are lack of physical activity, sedentary life style, cigarette smoking and alcohol consumption. Obesity has been found to contribute $55 \%$ of burden to $\mathrm{T} 2 \mathrm{D}$, alone.

In sub-Saharan Africa, the prevalence of diabetes was observed to be 15.5 million ( 6\%) in 2017 and might outpace other global regions. ${ }^{6}$ The likely reason behind this upsurge might be sub-Saharan African countries face number of hurdles to tackle growing burden of T2D that includes limited health care resources, social settings and high burden of other co-morbid conditions like AIDS, TB and malaria. ${ }^{7,8}$ Approximately, $69 \%$ of people in age group of $20-79$ years are living with T2D and going undiagnosed in sub-Saharan Africa. ${ }^{9}$ In Ethiopia the prevalence of non-communicable diseases, including hypertension, cardiovascular diseases and diabetes mellitus is increasing with changes in people's lifestyles. ${ }^{10} \mathrm{In}$ Ethiopia for year 2019, the estimated number of adult population affected by T2D has been found to be 1 to less than 10 million, whereas, the age adjusted comparative prevalence for $20-79$ years is quite more $>12 \% .{ }^{2}$ Although, in Ethiopia prevalence based studies on national level are lacking and there is no accurate figure yet. However, some regional studies were able to predict the estimated prevalence, but, still nationwide figure is not clear.

The mortality and morbidity caused by T2D can be prevented up-to some extent by self-care behavior that includes dietary habits, physical activity, abstinence of smoking and alcohol consumption, taking medicines on time and timely monitoring of blood glucose level. One of the studies revealed that older adults were on compliant with on-time medicine intake but, were poorly compliant to diet and self-glucose monitoring and exercise. While, $60 \%$ of the participants reported that understanding their diet according to T2D was biggest barrier in self -care behavior. ${ }^{11}$

This has been also suggested that T2D can be prevented or managed by life style and diet modifications. Various studies observed reduction in the incidence of T2D by maintaining a body mass index (BMI) of $25 \mathrm{~kg} / \mathrm{m}^{2}$, intake of high fibre in diet, regular exercise and abstinence of smoking and reduced alcohol consumption. ${ }^{5,12-15}$ Though, there is huge variation in data from different countries or studies about the self-care seeking behavior and its role in management of T2D. Also, the self-care behavior towards the disease management and its control also depends upon the demography and socio-economic conditions, health infrastructure in the studied population or region. Therefore, self-care seeking behavior studies are more important to study their effect on diabetes prevalence or incidence in the society or community and its management. The Nigist Eleni Mohammad Memorial Hospital, Hossana serves as main health facility 
in Hadiya zone of Southern Ethiopia and covers huge population from rural areas. Hence, the present study was conducted in Nigist Eleni Mohammad Memorial Hospital, Hossana, Southern Nations Natioalities and People's Region (SNNPR), Ethiopia to have an access on the patients' attitude towards the management of the disease.

\section{Methods:}

\section{Study Settings:}

The present study was conducted in Nigist Eleni Mohammad Memorial Hospital (NEMMH), Hossana, SNNPR. NEMMH is the only teaching and referral hospital in Hadiya zone, SNNPR.

\section{Study Design and Period:}

An institution based cross sectional study was conducted on patients visiting the hospital for blood glucose check-up or follow-up from 1st June to 30th June, 2018.

\section{Inclusion and Exclusion Criterion:}

All T2D patients > 18 years old who were on follow up visits to chronic diseases OPD in the hospital and able to respond included in the study. Severely ill T2D patients, not able to respond and individuals with hearing and speech impairment were excluded from the study.

\section{Source Population and Study Population:}

The source population included all adult T2D patient already on follow and study population included selected individuals from T2D follow-up patients in NEMMH, Hossana.

\section{Sample Size Determination:}

A single population proportion formula was used to calculate the sample size by using following assumptions: an anticipated proportion of self-care practice among diabetic patients $50 \%$, margin of error $5 \%$ and $10 \%$ contingency for the non-responders. Since, the source population for diabetic patients was < 10,000 , the final sample size was calculated to be 276 individuals using population correction formula.

\section{Sampling Techniques and Procedures:}

The patients already registered in the NEMMH, Hossana were only included in the study. The details of patients on diabetic medications were obtained from the hospital records and respondents were selected using random sampling method.

\section{Operational Definitions:}

The self-care behavior of T2D patients was measured on the basis of physical exercise, diet, medication and blood glucose measurement. Self-care behavior was considered as 'good self-care practice' if they 
scored $>60 \%$ of the total self-care practice questions and 'poor self-care practice' if they scored $<60 \%$ in the last three days.

\section{Data Collection Procedures:}

The data was collected by using pretested structured questionnaire adopted from different literatures which were designed to assess self-care practice of diabetic patients. Questionnaire was prepared in English language and translated to local language Hadiyissa and back translated to English by fluent speakers of the both the languages. Intensive training was given for supervisors and data collectors on the purpose of study, handling questionnaires, data collection and on ethical consideration of the participants. The data was collected by six trained nurses using face to face interview method. Additionally, three public health officers for supervision were recruited to participate and monitor the data collection. Five percent of the questionnaires were pre-tested before actual data collection. The data collectors were asked to submit data collected every day to their supervisors for completeness and consistency of the data. If, there was any error was immediately corrected on very next day to avoid the discrepancies.

\section{Variables:}

\section{Dependent variable}

Self-care behavior of T2D patients.

\section{Independent variables:}

Socio demographic and economic characteristics, knowledge about the T2D and constructs of Health Belief Model (perceived susceptibility, perceived severity, perceived benefits, perceived barriers and selfefficacy) were independent variables used in the study. The questionnaire was adopted from other studies with internal consistency of @=0.87. ${ }^{16,17}$ Diabetic self-care was measured using 10 items on parameters of physical exercise, diet, medication, blood glucose and sanitation (using comfortable shoes) measurement and was classified in two parts: 'good self-care practice' and 'poor self-care practice'. The respondents were considered following "good self-care" if they scored $>60 \%$ of the total self-care practices in the last three days. To analyze the Health Belief model, the perceived susceptibility (8 items), perceived severity (4 items), perceived benefits ( 7 items), perceived barriers ( 12 items) and selfefficacy (10 items) were measured, respectively. To these constructs, the response of $>80 \%$ was considered high, moderate response $(50-79 \%)$ and $<50 \%$ as the low response. The knowledge towards self-care management of diabetes was categorized into three parts: good knowledge (answered all the three questions), less knowledge (responder provide one or two correct answers) and no knowledge (incorrect answer for all the three questions). The body mass index (BMI) of the participants was calculated during routine checkup or follow up and categorized into underweight, normal and overweight (obese). 


\section{Data Processing and Analysis:}

The collected data was entered into Epi 3.1 and exported to SPSS 20.0 for further analysis. The frequency tables, graphs and descriptive summaries were used to describe the study variables. Analysis of logistic regression was done to determine the predictors of self-care behavior of T2D patients. Binary logistic regression analysis of Self-care Behavior of T2D patients was used to analyze dependent and independent variables and find significant association, if any.

In binary logistic regression analysis, variables with a $P$-value $\leq 0.25$ was considered as a candidate for multivariable analysis. The data was entered into multivariable logistic regression and a final model was obtained. Adjusted odds ratio with 95\% confidence interval that not include 1 and $P$-value $<0.05$ was computed to assess the statistical significance and strength of association between the dependent and predictor variables. Variables with $P$-value $<0.05$ in logistic regression were considered significantly associated with dependent variables. The model was considered fir or best, if the value for Hosmer and Lemeshow test was $>0.05(0.11)$.

\section{Results:}

\section{Socio-demographic Characteristics:}

A total of 276 diabetes patient were recruited in the study and $100 \%$ response rate was recorded. Out of 276 respondents, $133(48.3 \%)$ were male and $142(51.7 \%)$ females. The mean age was observed to be $49.7 \pm 14.3$ years. More than half of the individuals 163 (59.1\%) were married and large proportion of the participants $86(31.1 \%)$ completed education from 1st to 8 th grade only. The Hadiya ethnicity was observed to be dominant $150(54.34 \%)$ and majority of the participants $158(57 \%)$ were protestants. Housewives were found to be in majority $75(27.1 \%)$ among the participants followed by farmers 63 (22.7\%). The average monthly income was 660.50 Ethiopian Birr. The mean BMI of the participants was $22.8 \pm 3.9$, most of them $188(68.2 \%)$ were in the normal weight category, whereas, only $14(4.9 \%)$ were found to be obese (Table 1). 
Table 1

Distribution of respondents on the basis of socio-demographic characteristics.

\begin{tabular}{|c|c|c|c|}
\hline Variables & Category & Frequency & Percentage \\
\hline \multirow[t]{3}{*}{ Age Group } & $15-24$ & 20 & 7.2 \\
\hline & $24-65$ & 18 & 6.7 \\
\hline & $>65$ & 69 & 25.1 \\
\hline \multirow[t]{2}{*}{ Gender } & Male & 133 & 48.5 \\
\hline & Female & 142 & 51.2 \\
\hline \multirow[t]{4}{*}{ Marital Status } & Married & 163 & 59.1 \\
\hline & Single & 92 & 33.3 \\
\hline & Widowed & 11 & 3.9 \\
\hline & Divorced & 10 & 3.6 \\
\hline \multirow[t]{5}{*}{ Educational Status } & Illiterate & 72 & 26 \\
\hline & Read and Write only & 34 & 12.3 \\
\hline & $1-8$ & 86 & 31.1 \\
\hline & High School & 61 & 22.2 \\
\hline & Diploma and above & 23 & 8.33 \\
\hline \multirow[t]{6}{*}{ Occupation } & Government Employee & 22 & 7.9 \\
\hline & Farmer & 63 & 22.7 \\
\hline & Merchant & 57 & 20.7 \\
\hline & Housewife & 74 & 27.1 \\
\hline & Student & 46 & 16.7 \\
\hline & Others & 14 & 4.9 \\
\hline \multirow[t]{5}{*}{ Religion } & Protestant & 158 & 57 \\
\hline & Orthodox & 88 & 31.8 \\
\hline & Muslim & 16 & 5.8 \\
\hline & Catholic & 9 & 3.4 \\
\hline & Others & 5 & 1.8 \\
\hline \multirow[t]{2}{*}{ Ethnicity } & Hadiya & 150 & 54.34 \\
\hline & Kambata & 51 & 18.47 \\
\hline
\end{tabular}




\begin{tabular}{|c|c|c|c|}
\hline Variables & Category & Frequency & Percentage \\
\hline & Guragie & 34 & 12.3 \\
\hline & Silte & 27 & 9.78 \\
\hline & Others & 14 & 5 \\
\hline \multirow[t]{2}{*}{ Residence } & Urban & 67 & 24.9 \\
\hline & Rural & 209 & 75.1 \\
\hline \multirow[t]{3}{*}{ Monthly Income (Ethiopian Birr) } & $<1000$ & 119 & 43.1 \\
\hline & $1000-2000$ & 112 & 40.6 \\
\hline & $>2000$ & 45 & 16.4 \\
\hline \multirow[t]{3}{*}{ Weight } & $<39$ & 18 & 6.4 \\
\hline & $39-54$ & 160 & 58.1 \\
\hline & $>54$ & 98 & 35.5 \\
\hline \multirow[t]{3}{*}{ Height (in cms) } & $<150$ & 5 & 1.7 \\
\hline & $150-180$ & 230 & 83.4 \\
\hline & $>175$ & 41 & 14.9 \\
\hline \multirow[t]{3}{*}{ BMI } & Normal & 188 & 68.2 \\
\hline & Overweight & 74 & 26.9 \\
\hline & Obese & 14 & 4.7 \\
\hline
\end{tabular}

\section{Knowledge on Diabetes Mellitus:}

Majority of the respondents 208 (93.7\%) had knowledge about diabetes, whereas, $196(88.3 \%)$ of the respondents were knowledgeable about the sign and symptoms of diabetes. Approximately, 207 (93.2\%) of them were knowledgeable about diabetes self-care practices. Substantial proportion 170 (76.6\%) reported that regular exercise maintains the blood glucose level, while, $93(41.9 \%)$ of the respondents replied that not having breakfast after taking drug increases blood glucose level. Majority of the people 190 (85.6\%) had knowledge that non adherence to medication increases blood glucose level. whereas, $6.8 \%$ of them answered that all there commended food increases blood glucose level.

\section{Perceived Susceptibility and Severity:}

The perceived susceptibility to diabetes complications indicated that 191 (58.3\%) of the study respondents had moderate perceived susceptibility and the remaining $49(17.6 \%)$ and $36(13 \%)$ had high and less perceived susceptibility, respectively. Regarding perceived severity of diabetes and its related 
complications, a total of $139(50.5 \%)$ respondents had a moderate perceived severity. While, $110(39.8 \%)$ and 26 (9.5\%) participants had high and less perceived severity, respectively (Table 2).

Table 2

Distribution of respondents perceived susceptibility, perceived severity, perceived benefits and barriers.

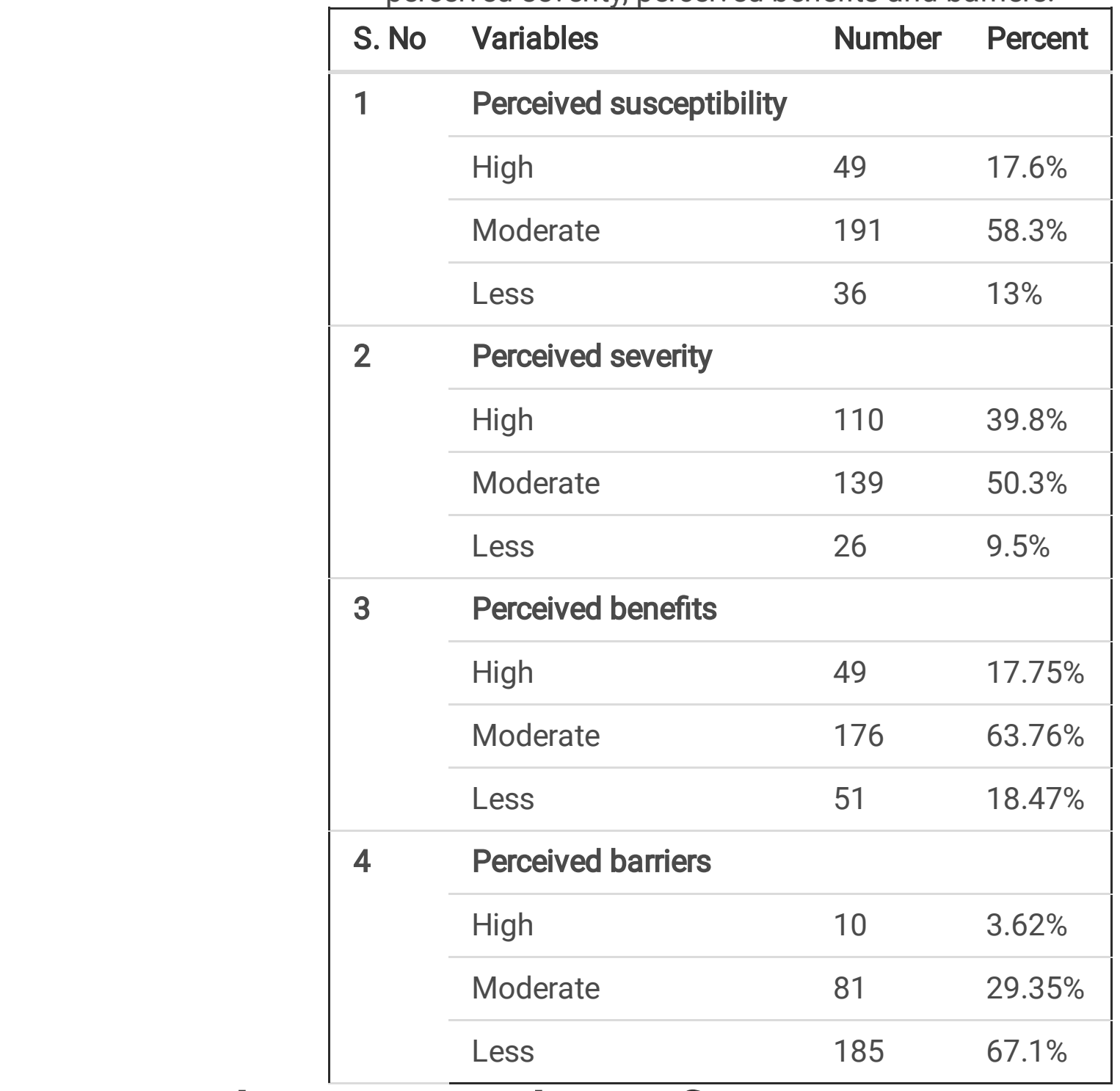

\section{Perceived Barriers and Benefits:}

The rate of high perceived barriers to self-care practice among respondents was limited. But, majority of the respondents 149 (67.1\%) had less perceived barrier followed by moderate perceived barriers 63 $(32.9 \%)$ to self-care practice to practice further complications related to diabetes mellitus. Furthermore, the perception of respondents about benefit of self-care indicated that majority of them $176(63.76 \%)$ had moderate perceived benefit of self-care practice. The remaining were followed by less perceived benefits $51(18.47 \%)$ and high perceived benefits 49 (17.75\%) towards benefits of self-care (Table 2).

\section{Self-care Practices:}

Out of total study respondents, only 119 (43.1\%) practiced the recommended self-care practices. Among the recommended self-care behaviors, $216(78.4 \%)$ of the respondents had taken the prescribed drugs 
appropriately, whereas, 148 (53.6\%) of them intake recommended dietary. Only 69 (31.1\%) of the individuals were habitual to exercise every day for thirty minutes (Fig. 1).

\section{Factors affecting Self-care Behavior of Diabetic Patients:}

Self-care behavior of diabetic patients was assessed for its association. Bivariate logistic regression analysis showed that frequent information, educational status, monthly income, occupation, perceived severity, perceived barriers and perceived benefits were significantly associated. But, when possible confounding variables were processed for multivariate binary logistic regression analysis only educational status, monthly income, perceived severity, perceived barriers remained significantly and independently associated with self-care behavior of diabetic patients. Literate individuals were observed to be 5.9 times more able to perform self-care than illiterate individuals $[A O R=5.9,95 \% \mathrm{Cl}(2.23-18.18), P$ $<0.001]$. On the other hand, diabetic patients with high income were 2.42 times more able to perform selfcare than individuals having less income $[\mathrm{AOR}=2.42,95 \% \mathrm{Cl}(1.04-17.95) P<0.05]$. Individuals with high perceived severity of the disease and its complications were 8.3 times more able to perform self-care than less perceived severity $[A O R=8.3,95 \% \mathrm{Cl}(1.19-16.25), P<0.001]$. Individuals who had moderate perceived barriers to self-care were 0.3 times less able to perform self-care than with less perceived barriers $[\mathrm{AOR}=0.57,95 \% \mathrm{Cl}(0.12-0.89), P<0.05]($ Table 3$)$. 
Table 3

Variables predicting Self-care behaviors of Diabetic patients in logistic regression.

Variable

Level of Self-care Practice

Yes

No

Crude Odds

Ratio

Adjusted Odds Ratio (AOR)

$95 \% \mathrm{Cl}$

(COR) $95 \% \mathrm{Cl}$

Frequent Information

Yes

98

(35.50\%)

59

(21.37\%)

$0.20(1.0-33.5)$

$2.07(0.19-7.9)$

No

184

21

(66.67\%)

$(6.61 \%)$

Educational Status

Literate

98

$(35.50 \%)$

86

(31.20\%)

$1.4(3.2-8.6)$

$5.9(2.23-18.18)$ **

Illiterate

41

(14.90\%)

51

(18.47\%)

1

1

Monthly Income

$\geq 2000 \quad 96$

(34.78\%)

41

(14.90\%)

$2.60(1.6-6.0)$

$2.42(1.04-17.95)^{\star}$

$<2000$

65

(23.55\%)

74

(26.81\%)

1

1

Occupation

Government

Employee

120

(43.48\%)

31

(11.23\%)

$11.00(1.6-$

6.9)

1

Farmer

34

(12.32\%)

$99 \quad 1$

(35.87\%)

1

1

Perceived Susceptibility

High Severity

133

(48.20\%)

36

(13.04\%)

Less

$24(8.70 \%)$

83

(30.07\%)

$3.1(0.4-6.2)$

$2.03(1.01-6.25)^{*}$

1

1

Perceived Severity

High

$$
\begin{array}{ll}
76 & 34 \\
(27.54 \%) & (12.31 \%)
\end{array}
$$

$4.8(2.4-9.2)$

$8.3(1.19-16.25)$ **

* P-value $<0.05$ considered statistically significant

** P-value $<0.001$ considered statistically significant 


\begin{tabular}{|c|c|c|c|c|}
\hline \multirow[t]{3}{*}{ Variable } & \multicolumn{4}{|c|}{ Level of Self-care Practice } \\
\hline & Yes & No & $\begin{array}{l}\text { Crude Odds } \\
\text { Ratio }\end{array}$ & $\begin{array}{l}\text { Adjusted Odds Ratio (AOR) } \\
95 \% \mathrm{Cl}\end{array}$ \\
\hline & & & (COR) $95 \% \mathrm{Cl}$ & \\
\hline Less & $\begin{array}{l}151 \\
(54.71 \%)\end{array}$ & $\begin{array}{l}15 \\
(5.43 \%)\end{array}$ & 1 & 1 \\
\hline \multicolumn{5}{|c|}{ Perceived Benefits } \\
\hline Moderate & $\begin{array}{l}98 \\
(35.50 \%)\end{array}$ & $\begin{array}{l}78 \\
(28.26 \%)\end{array}$ & $2.4(1.2-4.9)$ & 2. $(0.12-6.64)$ \\
\hline Less & $\begin{array}{l}47 \\
(17.07 \%)\end{array}$ & $\begin{array}{l}53 \\
(19.20 \%)\end{array}$ & 1 & 1 \\
\hline \multicolumn{5}{|c|}{ Perceived Barriers } \\
\hline Moderate & $\begin{array}{l}63 \\
(22.83 \%)\end{array}$ & $\begin{array}{l}28 \\
(10.14 \%)\end{array}$ & $2.4(1.2-4.9)$ & $0.57(0.12-0.89)^{\star}$ \\
\hline Less & $\begin{array}{l}99 \\
(35.86 \%)\end{array}$ & $\begin{array}{l}86 \\
(31.20 \%)\end{array}$ & 1 & 1 \\
\hline \multicolumn{5}{|c|}{ * P-value $<0.05$ considered statistically significant } \\
\hline \multicolumn{5}{|c|}{ ** P-value $<0.001$ considered statistically significant } \\
\hline
\end{tabular}

\section{Discussion:}

T2D (Type 2 Diabetes) is one of the major growing health problem. Write about the self-management of disease its prevalence and how it can be controlled by preventive measures life style. Diabetes prevalence is becoming a fast epidemic with people affected approximately going to double in next decade, especially in developing countries. The reasons are increased ageing that might be a factor in addition to already existing burden. Till date, no sure cure been identified for T2D. But, various treatment modalities like modification in the lifestyle, management of obesity, use of oral hypoglycemic agents and metformin (insulin sensitizer) reduced the resistance to insulin. ${ }^{18}$ Novel drugs are also being developed to manage the T2D. However, education and self-care practices has remain an important key factor to control this increasing burden and these factors should be tailored to improve the life quality of individuals with T2D. Hence, the present study was designed to assess the self-care behavior of T2D patients in Hossana, SNNPR, Ethiopia to assess the management strategies being adopted by them to control the disease burden.

In the present study, approximately $119(43.1 \%)$ patients practiced the recommended self-care practices which is lower than the study conducted in Gondar, Ethiopia (48.14\%). ${ }^{18}$ Similarly, the outcome of practicing the self-care practices in Hossana was lower than data from Palestine $48 \%,{ }^{19}$ Bangalore, India $50.5 \%,{ }^{20}$ Ardabil, Iran and Puducherry, ${ }^{21}$ India $63.6 \% .{ }^{22}$ However, the data generated to adopt self-care 
practices for T2D management is higher than other regional studies conducted in Ethiopia such as Dire Dawa and Harari hospitals. ${ }^{16}$ Also, it is much higher than study conducted in Tawam and Al-Ain hospital, UAE $15.3 \%{ }^{23}$ The likely reason behind this may the difference source population, age group included in the study and socio-economic conditions of the people.

Education plays an important role in the management of communicable, non-communicable and chronic diseases. The present study also revealed that individuals educated (minimum up to high school) were more adhered to better diabetic self-care activities when compared to others illiterate. Similarly, various other studies from Addis Ababa, ${ }^{24}$ Bahir Dar, ${ }^{25}$ Ghana ${ }^{26}$ and South Gondar ${ }^{27}$ also reported that education is more important in management of chronic diseases like T2D. The literacy rate of Ethiopia was $51.77 \%$ only in 2017 which is still poor and might be because of huge gap of education in urban and rural areas, big and small cities. Hence, the most probable reason towards poor adherence to diabetes self-care activities might be that participants with higher education do have knowledge about disease management, better informed or understand and practice the acceptable standards of self-care activities than non-educated participants.

Although, knowledge alone is not sufficient to change behavior of any individual, instead the attitude plays an important role. But, knowledge is more important to explain behavior changes in a patient to manage the diseases with efficiency. Findings from the present study showed that knowledge of the respondents about diabetes was high accounting 230 people (83.3\%); however, majority of them did not follow the recommended self-care practices. Though, knowledge is an essential factor for change in behavior or attitude of any individual, but, this change in behavior by its own alone also depends on individual circumstances. This is similar to the study conducted in Nigeria, where immense knowledge was reported in study participants about diabetic signs and symptoms, but, despite of this all they were lacking in adoption of self-care practices. ${ }^{28}$ Another study from Addis Ababa, Ethiopia also showed that knowledge about diabetes had no significant statistical association with glycemic control. ${ }^{24}$ This may be associated to factors such as high perceived barriers of self-care, less perceived severity of the disease and its complications, infrequent cues to action, low income and educational status. In one of the studies from Bengaluru, India, only $24.25 \%$ individuals had good knowledge for self-care practices, whereas foot care was the most neglected area observed. ${ }^{29}$ In Nigeria, negative attitude towards the disease condition was observed to be significantly associated with knowledge. ${ }^{30}$

Economy too plays a major role in self-care behavior practices. Findings from the present study indicates that patients with high income were two fold more likely to practice self-care than low income patients. Similarly, data generated from Jimma University and Nigeria corroborates that self-care behavior also depends on the monthly income of the patients. ${ }^{31}$ Individuals with high income can frequently visit the health facility for follow-ups and stick to the treatment too. The present study showed that patients with more perceived barrier were less likely to practice self-care than those with less perceived barrier. This is in line with the findings from Harari which indicated that people who had less perceived barrier to selfcare were better to perform self-care than moderate perceived barrier. On contrary, one of the studies from 
Jordan showed that increased perceived barriers to adherence was significantly associated to poor control of diabetes. ${ }^{32}$

The present study revealed that patients with high perceived susceptibility to diabetic complications will self-practice two fold more when compared to low perceived susceptibility. On contrary, study from Jordan revealed that individuals with high perceived susceptibility to diabetic complications were less likely perform their self-care practice than those with less perceived susceptibility. The possible reason for this difference might be the findings are in line with the constructs of the HBM assumption; where patients who had high perceived susceptibility the disease complication were more adherent to selfcare. $^{33}$

\section{Conclusion:}

The present study revealed slightly low self-care practices in population near Hossana town or Hadiya zone than others. Also, this was observed that BMI has no significant role in adoption of self-care practices. Along with frequent information or messages, educational status, high perceived severity and susceptibility enhances self-care behavior of diabetic patients, while, low income and high perceived barriers are the factors that inhibit self-care behavior in diabetic patients. Hence, we could infer that training should be given to the patients with respect to perceived severity of diabetes and how to overcome perceived barriers for self-care. Also, efforts should be put on providing more education, generating new income resources and increase the health infrastructure in rural areas so that the individuals can reach health care facilities for timely follow-ups.

Further studies are warranted in the region on qualitative data, adherence to the treatment and especially on genetic or biochemical aspects which can define the magnitude of the disease on the basis of host genetics and physiological conditions. More, population or GWAS studies are required in the region to identify the susceptible loci and accordingly local interventions can be devised for control and management of the disease.

\section{Declarations}

\section{Ethics Approval and Consent to Participate:}

The present study was ethically approved by Ethics Review Committee, College of Medicine and Health Sciences, Wachemo University. All the participants were well informed and explained the purposed of the study prior to their recruitment in the study.

\section{Consent for Publication:}

The information related to study participants was kept confidential.

\section{Availability of data and materials}


The data that support the findings of this study are available upon reasonable request

\section{Competing interests:}

The authors declare that they do not have any competing interests.

\section{Funding:}

The authors are thankful to Wachemo University for providing the research grant through minor research grant scheme.

\section{Authors' contributions}

LA conceived the study design, coordinated the research activities and analyzed the data. BE, AB and TT participated in data analysis and statistical techniques. TK, TS, AG, DS and TT participated in methodological part of the study. RP drafted the manuscript and reviewed all the analysis. All the authors have read and approved the final version of this manuscript.

\section{Acknowledgments}

The authors are thankful to data collectors and their supervisors for their commitment during data collection. Also, we appreciate the willingness of our study participants to provide their important information for smooth conduct of the study.

\section{References}

1. Saeedi P, Petersohn I, Salpea P, et al. Global and regional diabetes prevalence estimates for 2019 and projections for 2030 and 2045: Results from the International Diabetes Federation Diabetes Atlas. Diad Res Clin 2019;157:107843.

2. International Diabetes Federation Diabetes Atlas (9th ed.) 2019 update. Available from: http://www.idf.org/sites/default/files/5E_IDFAtlasposter_2019_EN.pdf

3. Chen L, Magliano DJ, Zimmet PZ. The worldwide epidemiology of type 2 diabetes mellitus-present and future perspectives. Nat Rev Endocr. 2012;8(4):228.

4. Genetic basis of type 1 and type2 diabetes, obesity, and their complications. Advances and emerging opportunities in diabetes research: a Strategic Planning report of the DMICC. www2.niddk.nih.gov/NR. (Accessed 22nd December 2011).

5. Ripsin CM, Kang H, Urban RJ. Management of blood glucose in type 2 diabetes mellitus. Am Fam Physician. 2009;79(1):29-36.

6. Zimmermann M, Bunn C, Namadingo H, Gray CM, Lwanda J. Experiences of type 2 diabetes in subSaharan Africa: a scoping review. Glob Health Res Policy. 2018;3(1):1-3.

7. Agyemang C, Meeks K, Beune E, et al. Obesity and type 2 diabetes in sub-Saharan Africans-Is the burden in today's Africa similar to African migrants in Europe? The RODAM study. BMC Med. 
2016;14(1):1-2.

8. Gill GV, Mbanya JC, Ramaiya KL, Tesfaye S. A sub-Saharan African perspective of diabetes. Diabetologia. 2009;52(1):8-16.

9. Sobngwi E, Ndour-Mbaye M, Boateng KA, et al. Type 2 diabetes control and complications in specialised diabetes care centres of six sub-Saharan African countries: the Diabcare Africa study. Diab Res Clin Prac. 2012;95(1):30-3

10. Gillibrand R, Stevenson J. The extended health belief model applied to the experience of diabetes in young people. Brit J Health Psych. 2006;(1):155-1

11. Aburuz SM, McElnay JC, Millership JS, Andrews WJ, Smyth S. Factors affecting self-care activities, postprandial plasma glucose and HbA1c in patients with type 2 diabetes. Int J Pharm Prac. 2002; (S1):R96.

12. Hu FB, Manson JE, Stampfer MJ, et al. Diet, lifestyle, and the risk of type 2 diabetes 22 mellitus in women. N Eng J Med. 2001;345(11):790-79

13. Willi C, Bodenmann P, Ghali WA, Faris PD, Cornuz J. Active smoking and the risk of type 2 diabetes: a systematic review and meta-analysis. 2007;298(22):2654-2664.

14. Yoon KH, Lee JH, Kim JW, et al. Epidemic obesity and type 2 diabetes in Asia. The Lancet. 2006;368 (9548):1681-168

15. Boffetta P, McLerran D, Chen Y, et al. Body mass index and diabetes in Asia: a cross-sectional pooled analysis of 900,000 individuals in the Asia cohort consortium. PloS 0 2011;6(6):e19930.

16. Ayele BH, Mengesha MM, Tesfa T. Predictors of self-care activities of outpatient diabetic residents in Harar and Dire Dawa: A hospital-based cross-sectional study. SAGE Open Med. 2019;7:2050312119865646.

17. Aschalew AY, Yitayal M, Minyihun A, Bisetegn TA. Self-care practice and associated factors among patients with diabetes mellitus on follow up at University of Gondar Referral Hospital, Gondar, Northwest Ethiopia. BMC Res No 2019;12(1):1-6.

18. Olokoba AB, Obateru OA, Olokoba LB. Type 2 diabetes mellitus: a review of current trends. Oman Med J. 2012;27(4):269.

19. Mosleh RS, Jarrar YB, Zyoud SE, Morisky DE. Factors related to diabetes self-care management behaviors among patients with type II diabetes in Palestine. J Appl Pharm Sci. 2017;7(12):102-10

20. Suguna A, Magal AS, Stany A, Sulekha T, Prethesh K. Evaluation of self-care practices among diabetic patients in a rural area of Bangalore district, India. Int J Curr Res Aca Rev. 2015;3(6):415-422

21. Nejaddadgar N, Solhi M, Jegarghosheh S, Abolfathi M, Ashtarian H. Self-care and related factors in patients with type 2 diabetes. Asian J Biomed Pharm Sci. 2017;7(61):6-10.

22. Selvaraj K, Ramaswamy G, Radhakrishnan S, et al. Self-care practices among diabetes patients registered in a chronic disease clinic in Puducherry, South India. J Soc Health Diab. 2016;4(01):02502 
23. Al-Maskari F, El-Sadig M, Al-Kaabi JM, et al. Knowledge, attitude and practices of diabetic patients in the United Arab Emirates. PloS 0 2013;8(1):e52857.

24. Berhe KK, Demissie A, Kahsay AB, Gebru HB. Diabetes self-care practices and associated factors among type 2 diabetic patients in Tikur Anbessa specialized hospital, Addis Ababa, Ethiopia-a cross sectional study. Int J Pharm Sci Res. 2012;3(11):4219.

25. Abate TW, Tareke M, Tirfie M. Self-care practices and associated factors among diabetes patients attending the outpatient department in Bahir Dar, Northwest Ethiopia. BMC Res Notes. 2018;11(1):15.

26. Mogre V, Abanga ZO, Tzelepis F, Johnson NA, Paul C. Adherence to and factors associated with selfcare behaviours in type 2 diabetes patients in Ghana. BMC End Dis. 2017;17(1):1-8.

27. Gezie GN, Alemie GA, Ayele TA. Knowledge and practice on prevention of hypoglycemia among diabetic patients in South Gondar, Northwest Ethiopia: institution based cross-sectional study. Integr Obes Diab. 2015;1(3):56-60.

28. Okolie VU, Ehiemere OI, Peace IN, Ngozi KI. Knowledge of diabetes management and control by diabetic patients at Federal Medical Center Umuahia Abia State, Nigeria. Int J Med Medical Sci. 2009;1(9):353-35

29. Dinesh PV, Kulkarni AG, Gangadhar NK. Knowledge and self-care practices regarding diabetes among patients with Type 2 diabetes in Rural Sullia, Karnataka: A community-based, cross-sectional study. J Fam Med Prim Care. 2016;5(4):847.

30. Jackson IL, Adibe MO, Okonta MJ, Ukwe CV. Knowledge of self-care among type 2 diabetes patients in two states of Nigeria. Pharm Pract. 2014;12(3).

31. Kamel NM, Badawy YA, El Zeiny NA, Merdan IA. Sociodemographic determinants of management behaviour of diabetic patients. Part II. Diabetics' knowledge of the disease and their management behaviour. East Med Health J. 1999;5(5):974-983.

32. Ayele K, Tesfa B, Abebe L, Tilahun T, Girma E. Self care behavior among patients with diabetes in Harari, Eastern Ethiopia: the health belief model perspective. PloS O 2012;7(4):e35515.

33. Al-Sahouri A, Merrell J, Snelgrove S. Barriers to good glycemic control levels and adherence to diabetes management plan in adults with Type-2 diabetes in Jordan: a literature review. Patient Pref Adhe. 2019;13:675.

\section{Figures}




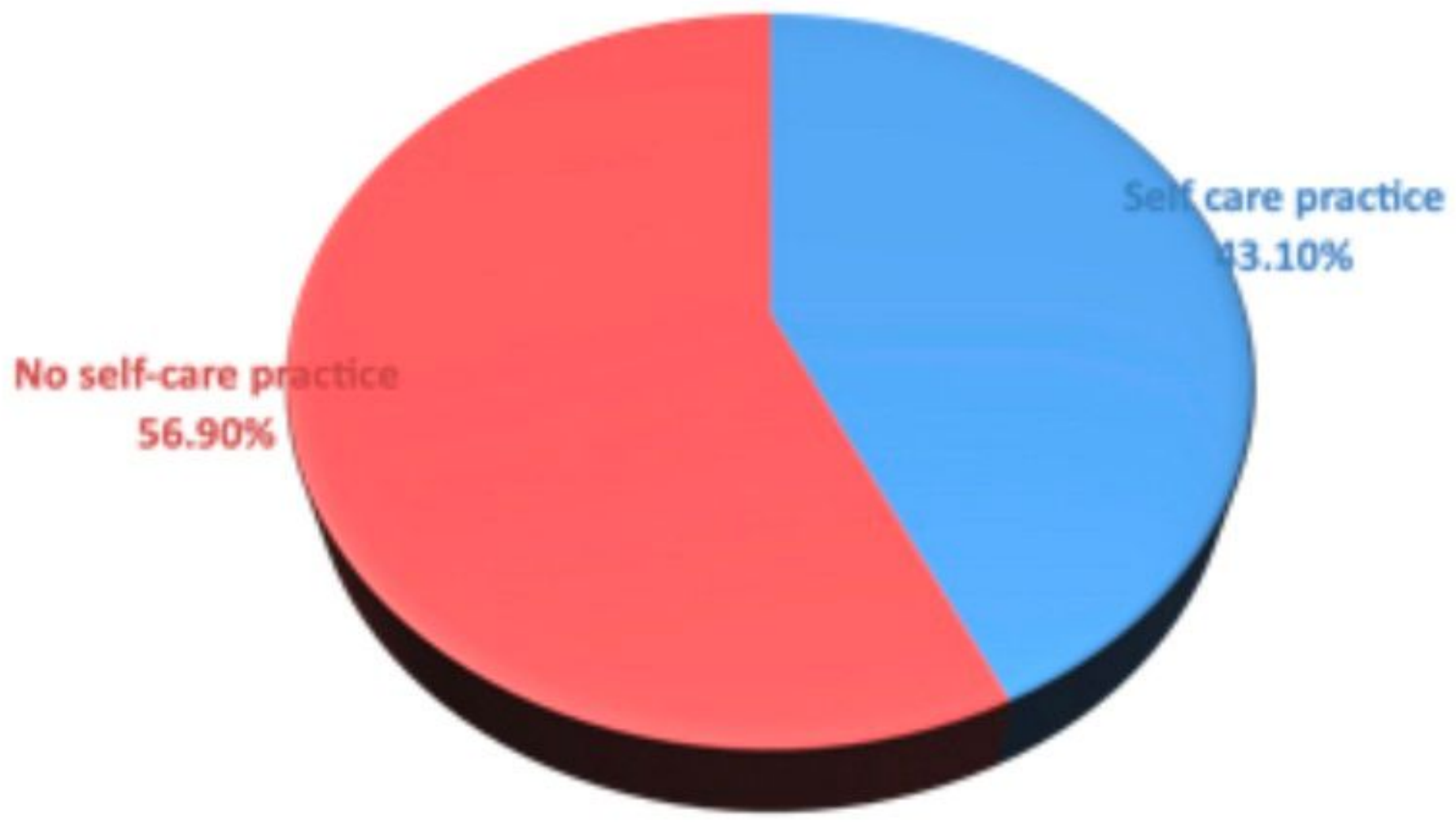

Figure 1

Self-care behaviour of Diabetic patient 